\title{
Ultrasound-guided distal adductor canal catheter placement for continuous postoperative analgesia in lower leg surgery
}

\author{
Alt ekstremite cerrahisinde postoperatif ağrı kontrolü için ultrason eşliğinde distal \\ adduktor kanala kateter yerleştirilmesi
}

Onur BALABAN, (1) Tayfun AYDIN, (ok Lokm DEMIR

To the Editor,

Distal adductor canal block is performed under ultrasound guidance by administering high volume of a local anesthetic into the adductor canal, close to the hiatus. ${ }^{[1]}$ Local anesthetic injection into the adductor canal leads to its distribution, thus reaching the sciatic nerve in the popliteal fossa. ${ }^{[2]}$ Single injection into the adductor canal at the distal hiatus level blocks both the sciatic and saphenous nerves and provides analgesia at the lower leg, ankle, or foot. ${ }^{[3,4]}$ We would like to present a case of ultrasound-guided catheter placement to the adductor canal for continuous postoperative analgesia in lower leg surgery.

Written informed consent was obtained for the publication of this report. The patient was a 23-year-old male who was operated for second, third, and fourth metatarsal fractures. The operation started under spinal anesthesia; however, spinal block was worn off due to elongation of the surgery, and the local anesthesia was converted to general. The surgery continued for $3.5 \mathrm{~h}$. After the surgery, the patient suffered from pain with an intensity of $8 / 10$, evaluated by the numerical rating score (NRS) system. We performed ultrasound-guided single injection distal adductor canal block at post anesthesia unit using $30 \mathrm{ml}$ of $0.25 \%$ bupivacaine. Pain intensity decreased to $0 / 10$ in $20 \mathrm{~min}$, and the patient was shifted to the surgery ward. After $4 \mathrm{~h}$, the patient reported pain, which was rated as $6 / 10$. We decided to place a catheter to the distal adductor canal under ultrasound guidance for prolonged analgesia. The patient was in prone position during the procedure. After providing sterile conditions, a high frequency linear probe was placed transversally at the medial side of $1 / 3$ distal thigh, and a cross-sectional image of the femoral artery was obtained. The needle was inserted in the anteriorto-posterior direction using the in-plane technique at the distal hiatus level of the adductor canal (Fig. 1a). When the tip of the needle reached the posterior of the sartorius muscle, $30 \mathrm{ml}$ of $0.25 \%$ bupivacaine was administered. Distribution of the local anesthetic solution was observed, in real time, posteriorly to the sartorius muscle and around the artery (Fig. 1b). A peripheral nerve catheter (Techniplex, Vygon, Ecouen, France) was placed through the needle into the area, which was enlarged due to the local anesthetic solution. After $20 \mathrm{~min}$, the intensity of pain re-

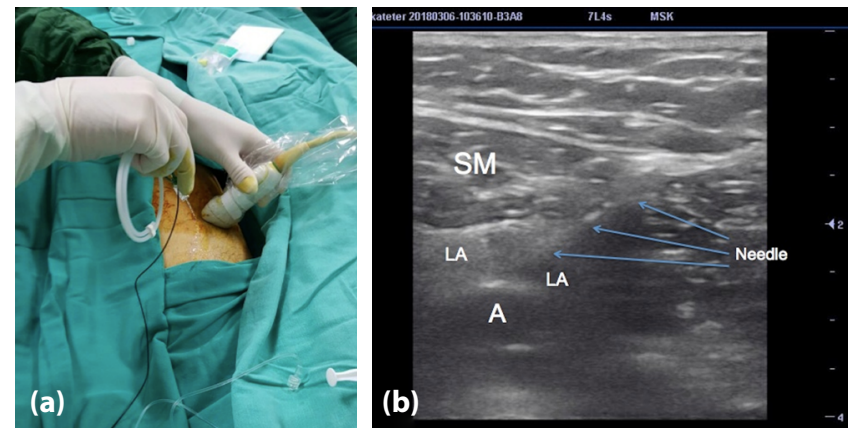

Figure 1. (a) Position of the ultrasound probe and needle during catheterization. (b) Ultrasound image showing the needle in the adductor canal and spread of the local anesthetic solution. A: artery; SM: sartorius muscle; LA: local anesthetic. 
duced to $0 / 10$. The patient needed a second dose 3.5 $\mathrm{h}$ after the catheter placement, third after $7 \mathrm{~h}$, and fourth after $11 \mathrm{~h}$, with the administration of $10 \mathrm{ml}$ of $0.25 \mathrm{ml}$ bupivacaine. The catheter was withdrawn after $36 \mathrm{~h}$, and the patient was discharged after 2 days of stay in the hospital without any complications. No motor block was observed in the patient during the treatment. Distal adductor canal blocks are usually performed for analgesia at the lower leg, and low concentrations of the local anesthesia are usually administered. In previous anecdotal reports, no motor block involving the sciatic nerve was reported..$^{[1,4]}$ Also, because the needle was not directly advanced around the sciatic nerve, high accumulation of drugs around the nerve leading to motor block was not expected.

Continuous and sufficient analgesia was achieved at the lower leg with adductor canal catheter place- ment in our case. Distal adductor canal block has the advantage of blocking both sciatic and saphenous nerves with a single injection in the prone position, and continuous postoperative analgesia is possible with catheter placement.

\section{References}

1. Morozumi K, Takahashi H, Suzuki T. Distal adductor canal block for administering postoperative analgesia in lower limb surgery. J Clin Anesth 2018;44:44. [CrossRef]

2. Andersen $\mathrm{HL}$, Andersen SL, Tranum-Jensen J. The spread of injectate during saphenous nerve block at the adductor canal: a cadaver study. Acta Anaesthesiol Scand 2015;59(2):238-45. [CrossRef]

3. Marian AA, Ranganath $Y$, Bayman EO, Senasu J, Brennan TJ. A Comparison of 2 Ultrasound-Guided Approaches to the Saphenous Nerve Block: Adductor Canal Versus Distal Transsartorial: A Prospective, Randomized, Blinded, Noninferiority Trial. Reg Anesth Pain Med 2015;40(5):623-30.

4. Tulgar S, Selvi O. Ultrasound guided distal adductor canal block provides effective postoperative analgesia in lower leg surgery. J Clin Anesth 2018;45:51. [CrossRef] 